\title{
Psicologia e Educação: Hoje e Amanhã
}

\author{
José Fernando Bitencourt Lomônaco ${ }^{1}$ \\ Instituto de Psicologia / USP
}

\begin{abstract}
Resumo
O papel do conhecimento psicológico na educação é considerado levando em conta o passado e as várias perspectivas teóricas da Psicologia, atuando para a solução de problemas educacionais hoje. O papel da Psicologia na Educação de amanhã não é uma questão fácil de responder, mas há necessidade de uma concepção psicológica mais completa sobre a natureza humana.

Palavras chaves: psicologia escolar, psicologia educacional, educação.
\end{abstract}

\section{Psychology and Education: to day and tomorrow}

\section{Summary}

The role of the psychological knowledge in the education is considered taking in consideration the past and the various theoretical views of Psychology working in order to solve educational problems to day. The role of the Psychology in the Education tomorrow it is not an easy question to be answered but there are a need of one more complete Psychological conception about the human nature.

Key words: school psychology, educational psychology, education.

Em primeiro lugar, gostaria de agradecer o honroso convite que me foi formulado pela Associação Brasileira de Psicologia Escolar para proferir a conferência de abertura deste IV Congresso Nacional de Psicologia Escolar. Ao receber este convite, fiquei me perguntando as razões que levaram a diretoria da ABRAPEE a escolher meu nome, quando os de muitos outros poderiam ter sido lembrados. Porém, uma vez aceito o convite, dediquei-me a refletir sobre como eu poderia desenvolver o tema de modo a relatar-lhes a minha visão a respeito das interfaces entre a Psicologia e a Educação, traçando um panorama histórico desta relação ao longo do tempo. Para elaborar minha palestra servi-me de três fontes:

$1^{\text {a }}$. minha experiência ao longo de 30 anos de carreira acadêmica, como professor de disciplinas ligadas ao ensino, tais como Psicologia Educacional e Psicologia da Aprendizagem; nestas três décadas pude acompanhar o aparecimento e o declínio de teorias e tecnologias ligadas ao processo educacional;

$2^{\text {a }}$. leituras de trabalhos de autores preocupados com as aplicações da teoria psicológica ao ensino em sala de aula, analisando as possibilidades e limitações desta aplicação e,

$3^{\mathrm{a}}$. entrevistas com professores/pesquisadores com ampla vivência nas áreas de desenvolvimento, aprendizagem e psicologia escolar. A partir deste conjunto de dados, elaborei a presente palestra que ora submeto à consideração e análise crítica desta seleta platéia de psicólogos preocupados com a educação escolar.

Em resposta à questão A Psicologia pode melhorar o ensino?, diferentes opiniões foram

\footnotetext{
${ }^{1}$ Endereço: Rua Mathews Grow, 79, Pinheiros CEP: 05406-100 São Paulo-SP - Brasil.
} 
manifestadas ao longo dos anos. Em 1899, William James, numa palestra aos professores - Talks to Teachers - afirmava com convicção: "... O ensino, de fato é uma arte. A ciência da psicologia não pode prestar-lhe a menor ajuda no tocante às estratégias específicas da instrução." O que teria levado William James a negar de forma tão peremptória, a possibilidade da Psicologia contribuir para a melhoria do ensino? Talvez o conjunto de conhecimentos e o objeto de estudo da Psicologia no final do século passado não propiciasse mesmo condições de contribuir efetivamente para o ensino em sala de aula. Porém, em nossos dias, tal colaboração é possível e fecunda?

Ainda que alguns autores pareçam duvidar desta possibilidade, fica-me a impressão de que a maior parte dos estudiosos admite atualmente que a aplicação de conhecimentos psicológicos para a compreensão dos processos de desenvolvimento e aprendizagem do aluno não é apenas possível, mas altamente desejável, para não dizer indispensável.

Travers (1972), por exemplo, mostra-se bastante otimista quando analisa as possíveis contribuições da Psicologia à Educação. Referindo-se especificamente à influência da Psicologia da Aprendizagem no ensino escolar, afirma:

Desde há muito tempo, a Psicologia da Aprendizagem tem sido considerada como tendo a chave para melhorar a educação. A esperança era a de que, com o desenvolvimento de uma ciência da aprendizagem, as crianças seriam capazes de aprender mais em menos tempo. (...) Algumas das previsões mais otimistas a respeito do impacto de uma ciência da aprendizagem vieram dos psicólogos. Essas previsões prometiam que a nova ciência da aprendizagem produziria uma dramática revolução na educação, mas as mudanças resultantes na educação não tiveram de fato, este caráter. Elas foram lentas e contínuas, embora altamente significantes ao longo deste meio século. Todavia, nem o leigo, nem o cientista, precisam ficar desapontados pelo fato da emergente Psicologia da Aprendizagem não ter produzido uma revolução educacional, pois a lenta evolução da educação que ela produziu foi de grande importância (p. 3).

Considera este autor, pois, que o caráter gradual das mudanças em educação, provocadas pelo impacto da Psicologia da Aprendizagem, é o que torna difícil a uma geração reconhecer as mudanças ocorridas. Como exemplo, lembra com propriedade as profundas mudanças ocorridas no mobiliário das modernas salas de aulas. Relata-nos que, em 1896, quando John Dewey fundou sua escola experimental na Universidade de Chicago, teve grande dificuldade em comprar ca11eiras móveis para as salas de aulas. Hoje, a dificuldade seria exatamente a oposta, qual seja, a de encontrar aquelas tradicionais cal1eiras fixadas no assoalho das salas de aulas. Tal mudança atesta 0 reconhecimento da importância da flexibilidade no planejamento da instrução, incompatível com arranjos físicos que prendem os alunos em suas carteiras.

Outros aspectos são ainda lembrados por este autor. A criança que algumas décadas passadas não conseguia aprender era rotulada de preguiçosa, desmotivada, sem força de vontade, burra e outros adjetivos do gênero, buscando-se a causa do fracasso escolar inteiramente no aluno e absolvendo a instituição escolar de quaisquer responsabilidades pelo mau desempenho dos estudantes. Hoje, certamente, psicólogos e educadores são muito mais críticos em relação ao papel da escola no tocante ao fracasso escolar. Também uma comparação entre o material escolar atualmente utilizado pelos alunos com o de décadas atrás revela enormes diferenças. Ao invés de livros-texto pobremente impressos, com poucas figuras, reduzidíssimo uso de cores e assuntos muito distantes do interesse dos alunos, o que vemos hoje são livros belamente impressos, repletos 
de figuras coloridas, nível de dificuldade de leitura controlado, assuntos mais próximos ao interesse dos alunos, com inclusão de jogos e exercícios que motivam a revisão do material estudado. Da mesma maneira, as disciplinas ou matérias que fazem parte do currículo foram selecionadas em função de sua presumível importância para a formação escolar do aluno, e não visando disciplinar a mente e desenvolver determinadas capacidades, tal como propugnava a influente Teoria da Disciplina Formal, vigente no início do século e tão bem refutada pelos trabalhos de Thorndike. Enfim, as escolas mudaram e muito desta mudança pode legitimamente ser atribuída aos trabalhos de uma legião de psicólogos preocupados com os processos de desenvolvimento e aprendizagem.

\section{A Psicologia e a Melhoria da Educação}

Mas, de que maneira a Psicologia exerceu sua influência sobre a prática escolar? Poder-se-ia pensar que o impacto da Psicologia na Educação decorreu de estudos feitos por psicólogos no ambiente escolar, procurando identificar as múltiplas variáveis das quais o comportamento de ensinar/aprender é função. Entretanto, como salienta Travers (1972), quando se faz um retrospecto histórico das contribuições da Psicologia para a Educação, verifica-se com certa surpresa, que muito pouca mudança pode ser atribuída ao trabalho direto de psicólogos nas escolas. Na verdade, os três psicólogos cujo trabalho produziu o maior impacto nas escolas, quais sejam Thorndike, Skinner e Piaget, não realizaram pesquisas em salas de aulas, preferindo desenvolver conhecimento no laboratório ou através da observação natural. O conhecimento desenvolvido por Thorndike levou à elaboração de livros-texto e dicionários escolares, à modificação de trabalhos literários de modo a torná-los legíveis para as crianças e ao planejamento de procedimentos para o ensino de aritmética e álgebra. A partir do trabalho de Skinner, muitas aplicações foram derivadas: instrução programada, sistema personalizado de instrução, técnicas de modelagem de respostas adequadas, exclusão da punição no processo de ensino, sistema de vales etc. Inegável também é a profunda influência das descobertas de Piaget em sala de aula: elaboração de programas para o ensino de ciências e matemática, a utilização dos jogos no contexto escolar e, atualmente (pelo menos em nosso meio), a avassaladora presença do construtivismo como teoria orientadora do processo de alfabetização.

Pode-se contrastar tal sucesso com o relativo fracasso daqueles que, em tempos mais recentes, propõem um ataque frontal aos problemas de caráter psicológico pesquisando diretamente nas escolas e, freqüentem ente, conduzindo programas de pesquisas que envolvem altíssimo custo financeiro. A realidade parece ser a de um retorno muito mais modesto do que o proporcionado pelas descobertas oriundas dos laboratórios. .

Todavia, com demasiada freqüência se espera dos cientistas de laboratório que forneçam uma série de receitas prontas para uso imediato em sala de aula. Este certamente não é o caso e revela um desconhecimento por parte do leigo a respeito da maneira pela qual as descobertas da ciência são aplicadas na vida diária. Lembranos Travers (1972) que no início, a física newtoniana não proporcionava aos engenheiros prescrições que estes profissionais pudessem aplicar direta e imediatamente na construção de pontes, mas forneceu um conhecimento que tomou a construção de pontes um procedimento mais efetivo e sistemático do que o que vinha sendo utilizado nos séculos anteriores. O construtor de pontes não mais precisava advinhar onde as pressões mais fortes iriam ocorrer; isto poderia ser determinado aplicando os princípios da física. Ou seja, a física 
proporcionou aos engenheiros maneiras de pensar a respeito da construção de pontes e algumas técnicas gerais de solução de problemas. Proporcionou também, uma linguagem técnica que ele poderia usar para descrever precisamente o que acontece quando uma carga é aplicada à ponte. $\mathrm{O}$ construtor poderia deixar de lado a linguagem imprecisa e confusa da vida diária e descrever precisamente as especificações do projeto. $\mathrm{O}$ que o autor quis mostrar com este exemplo é que a construção de pontes não passou por uma súbita revolução: as mudanças inicialmente foram sutis, sendo percebidas mais pelos especialistas do que pelo leigo.

A analogia entre a física e a engenharia parece aplicar-se igualmente bem à relação entre a Psicologia e a Educação. O impacto das descobertas psicológicas oriundas dos laboratórios também foi lento e sutil mas, ao longo dos anos, provocou substanciais mudanças nas práticas escolares. Analisar tal relação em nossos dias e hipotetizar o futuro dessa relação é o tema e o objetivo do presente trabalho.

\section{Psicologia e Educação: Hoje}

Nosso século testemunhou o aparecimento de três grandes conjuntos de teorias psicológicas que refletem a maneira pela qual os psicólogos vêem o papel da escola no desenvolvimento psicológico das crianças. Um primeiro conjunto vê a escola como um local privilegiado para a aplicação de conhecimentos derivados de estudos e pesquisas realizados fora do âmbito escolar. Inserem-se neste grupo, a meu ver, as concepções behavioristas e piagetianas. De acordo com essas concepções, embora o desenvolvimento possa ocorrer fora da escola, pois o fundamental não é o local mas os princípios e sua correta aplicação, a escola, face a sua organização que permite reunir muitas e diferentes crianças num mesmo espaço, possibilita avaliar a aplicação de princípios psicológicos a um grande número de sujeitos. Uma segunda maneira de encarar a relação entre a Psicologia e a Educação, acredita que a escola promove o desenvolvimento psicológico. Ou seja, o trabalho realizado dentro das salas de aulas no processo ensino-aprendizagem, favorece o desenvolvimento psicológico em vários aspectos sociais, afetivos e cognitivos. Um exemplo desse tipo de concepção é, a meu ver, a teoria sócio-histórica de Vygotsky, que salienta a importância do ensino escolar para o desenvolvimento de conceitos científicos. Finalmente, a terceira maneira de ver a relação Psicologia-Educação, defende que a escola não é um elemento decisivo para o desenvolvimento psicológico, podendo até mesmo atrapalhá-lo. Inserem-se claramente dentro desta concepção as críticas de Rogers que ele denomina de escola tradicional e algumas vertentes da psicanálise.

Esta maneira de encarar a atuação da psicologia dentro das escolas, em nossos dias, refletiuse no aparecimento de três grupos de teorias psicológicas aplicadas ao ensino, quais sejam: o behaviorismo, o cognitivismo e o humanismo. Vejamos, brevemente, algumas de suas características e implicações.

A abordagem behaviorista, fiel a suas origens históricas, enfatiza grandemente o papel do ambiente no desenvolvimento dos organismos, limitando-se ao estudo dos comportamentos manifestos e mensuráveis, descartando à consideração de eventos internos que ocorrem na mente do indivíduo e atuariam como mediadores entre os estímulos e as respostas. Não há dúvida de que as implicações desta teoria para o ensino escolar foram muito grandes e diretas. Ela estimulou o 
aparecimento de uma tecnologia educacional que desenvolveu um conjunto variado de instrumentos para auxiliar o professor a resolver os múltiplos problemas de sala de aula. Como exemplos ilustrativos temos a Instrução Programada e o Sistema Personalizado de Instrução, que buscaram dar ao professor instrumentos que garantissem a aprendizagem efetiva de informações por todos os alunos, respeitando-se as diferenças individuais refletidas no ritmo de aprendizagem de cada aluno. Propiciou também o desenvolvimento de variadas técnicas de controle do comportamento, tal como o Sistema de Vales, que visam dar ao professor recursos para enfrentar problemas comuns de sala de aula - a indisciplina, a falta de motivação dos alunos, a ausência de hábitos desejáveis de higiene, limpeza, pontualidade etc. Contrapondo-se a formulações extremamente vagas e imprecisas de objetivos educacionais características dos manuais escolares, esta tecnologia exige que o psicólogo e/ou professor explicitem claramente os objetivos a serem atingidos, os comportamentos a serem modificados e a maneira pela qual os resultados serão avaliados. Em função da grande influência e do prestígio que o comportamentalismo desfrutou na psicologia mundial e brasileira alguns anos passados, tais instrumentos difundiram-se rapidamente em nosso meio. Livros-texto sob forma de Instrução Programada e manuais para professores eram abundantes, cursos de difusão eram ministrados a professores, artigos em revistas especializadas e de divulgação relatavam a aplicação de técnicas comportamentais em sala de aula. Fazendo-se hoje um retrospecto, caberia perguntar o porquê do relativo esquecimento de recursos e procedimentos outrora tão prestigiados.

A concepção cognitivista enfatiza os processos internos através dos quais o mundo exterior é representado dentro do organismo. Contrariamente à abordagem compol1amentalista, enfatiza a importância dos eventos organísmicos que intervém entre o estímulo e a resposta, pois, como salientam Spinillo e Roazzi (1989):

... a resposta dada a determinada situação-estímulo... não depende apenas do estímulo apresentado, mas de processos mentais internos presentes na mente de um indivíduo em um momento determinado do seu desenvolvimento e em função de elaborações anteriores que tenham sido efetua das (p.22).

Em termos de implicações para a educação, poderemos dizer que a concepção cognitiva foi tão ou até mais fértil do que a comportamentalista. É inegável a esmagadora influência que as idéias de Piaget tiveram e ainda têm como teoria explicativa dos vários aspectos do desenvolvimento infantil. Algumas pesquisas têm demonstrado que os professores, quando indagados a respeito de suas predileções teóricas, apontam predominantemente a concepção piagetiana como a que eles consideram mais adequada para orientar sua ação pedagógica (embora na prática, suas ações não pareçam ser orientadas por ela).

Duas outras concepções, advindas da psicologia norte-americana, influenciaram também, ainda que menos intensamente que a teoria piagetiana, a educação escolar. Refiro-me às idéias de Jerome Bruner e David Ausubel sobre o desenvolvimento cognitivo e a aprendizagem em sala de aula. Em ambos os casos, é patente a preocupação em derivar do conhecimento psicológico princípios orientadores da ação do professor. Curiosamente, os princípios derivados não levaram esses autores a percorrer os mesmos caminhos e a fazer as mesmas recomendações. Se, de um lado, Bruner enfatiza a aprendizagem por descoberta, levando o aluno a indutivamente formular 
princípios e regras gerais, de outro lado, Ausubel defende a transmissão do conhecimento caminhando do geral para o particular, das definições para os exemplos, à moda de uma boa aula expositiva.

Atualmente, esta abordagem vem se interessando grandemente pelos processos através dos quais a informação é transformada, armazenada, recuperada e aplicada. Parte substancial dos psicólogos cognitivos vem se dedicando desde a década de 50, a procurar entender os processos envolvidos no processamento da informação. Em função de tais estudos, têm sido postulados mecanismos responsáveis pela codificação, armazenamento e recuperação da informação. Os estudos são numerosos e sofisticados, porém, as conclusões de tais pesquisas, a meu ver, ainda não se concretizaram em princípios aplicáveis à escola.

Finalmente, a orientação humanística preocupa-se fundamentalmente com os aspectos afetivos da aprendizagem. Embora afirmando uma preocupação com o ser humano como um todo, sem privilegiar o intelecto, na verdade a ênfase recai sobre aspectos não-cognitivos. O ser humano é visto como possuindo um potencial a ser desenvolvido, com uma natureza que tende naturalmente para a auto-realização desde que possa desenvolver-se em ambiente não-punitivo e não restritivo. De maneira geral tais concepções, dentre as quais a aprendizagem centrada no aluno postulada por Rogers, é o exemplo mais conspícuo, vê a escola tradicional como um ambiente que impede a autorealização do aluno e o seu crescimento pessoal. Na verdade, a abordagem humanista não deu origem a qualquer teoria de aprendizagem. No máximo, e com alguma boa vontade, a concepção rogeriana poderia ser vista mais como uma teoria de personalidade do aluno que aprende, com ênfase especial à interação professor-aluno. O que esse tipo de abordagem produziu foram propostas, geralmente rotuladas como utópicas e/ou revolucionárias, de uma total reformulação na instituição escolar subvertendo completamente os papéis de professores e alunos. Até onde chega meu conhecimento, não tenho notícias de escolas que tenham aplicado integralmente a proposta rogeriana, com exceção da conhecidíssima Summerhill que, na verdade, é anterior ao próprio Rogers.

Como se pode depreender desta breve exposição, tais orientações tenderam naturalmente a concentrar sua atenção preferencial em um dos três aspectos que fazem palie da natureza humana: a ação, a cognição e a emoção. Nisto reside, a meu ver, suas qualidade e suas limitações. Qualidades na medida em que isto conduziu naturalmente a uma análise aprofundada de cada uma das facetas privilegiadas pelas concepções em voga - o comportamento ou desempenho pelo behaviorismo, a cognição pelo cognitivismo e os aspectos afetivos pelas abordagens humanistas. Limitação porque, embora sem negar frontalmente a importância dos outros dois fatores, na prática, concentraram sua preocupação em apenas um deles. O resultado, como não poderia deixar de ser, é um retrato imperfeito e incompleto do aluno que aprende. Necessárias se fazem abordagens mais abrangedoras que, de maneira integrada e equilibrada, levem em conta esses três grupos interpenetrantes de fatores envolvidos na aprendizagem escolar.

No que toca especialmente à Psicologia Escolar, estes últimos anos testemunharam uma acesa discussão entre visões conflitantes do papel do psicólogo nas escolas. Esta discussão dividiu a comunidade entre aqueles que esperam do psicólogo uma atuação de caráter mais técnico nas escolas, geralmente de avaliador das capacidades dos alunos, e aqueles mais atentos aos seus determinantes sociais e institucionais. Como uma decorrência do trabalho daqueles que advogam uma atuação de caráter mais técnico, temos os controvertidos laudos psicológicos que tanta celeuma 
têm provocado entre psicólogos e educadores pelas conseqüências nefastas para a vida futura dos alunos. Correspondendo freqüentem ente aquilo que as escolas esperam dos psicólogos, muitos profissionais têm se esmerado no trabalho de avaliação intelectual através de uma variedade de testes, nem sempre conscientes da imprecisão e da relatividade das medidas psicológicas, assim como do próprio conceito de inteligência. Ainda que o objetivo de tais esforços pareçam, pelo menos à primeira vista meritórios, qual seja, o de colocar alunos em classes especiais nas quais eles tenham melhores condições de aprendizagem, na vida real o que freqüentemente ocorre é a estigmatização de alunos para todo o restante de sua vida escolar.

Contrapondo-se a esta visão tecnicista, uma outra ve11ente da Psicologia Escolar defende de maneira enfática que o psicólogo só pode entender realmente a escola e o aluno se estiver atento à dinâmica da instituição. Neste sentido, seu trabalho é muito menos o de um aplicador de testes e muito mais o de alguém voltado ao trabalho com professores, procurando entender e explicitar as expectativas dos mesmos em relação a alunos de classes economicamente desfavorecidas, analisando a forma pela qual a instituição se apropria da informação que lhe é trazida, discutindo com o corpo docente as múltiplas formas de queixa escolar, procurando facilitar o trabalho em equipes multidisciplinares, enfim, atuando muito mais junto ao professor do que no trabalho de avaliação dos alunos.

Essas duas formas de atuação e de concepção do papel do psicólogo escolar coexistem, às vezes em franco antagonismo. Conciliar ambas as orientações, reduzindo o antagonismo latente, é tarefa urgente nesta área de estudo e aplicação do conhecimento psicológico.

São essas, no meu entender, algumas interfaces entre a Psicologia e a Educação que podem ser atualmente identificadas nas escolas. Mas, e o amanhã? Que tendências se delineiam presentemente e quais os seus reflexos sobre a Psicologia Escolar, Educacional e da Aprendizagem no início do próximo século? É o que será considerado, a seguir.

\section{Psicologia e Educação: Amanhã}

É um truísmo afirmar que, a partir do presente, é possível se vislumbrar o futuro. Ainda que possível, as previsões certamente diferirão entre diferentes estudiosos. E isto porque ela implica em diferentes pontos de partida, representados pelo conhecimento e familiaridade do estudioso com sua área de interesse, além de envolver uma certa dose de subjetividade. Inicio, pois, essas conjecturas sobre os caminhos futuros da relação Psicologia-Educação a partir desta consideração, enfatizando o caráter idiossincrático dessas colocações, uma vez que elas resultam fundamentalmente de minhas experiências pessoais ao longo de muitos anos de docência universitária, trabalhos de campo e reflexões teóricas.

Um primeiro aspecto que me chama a atenção é a renovação do interesse pela influência das primeiras experiências sobre o desenvolvimento do organismo e suas poderosas implicações para a futura aprendizagem. Desta promissora interface entre a Psicologia e a Biologia, ou mais especificamente com as Neurociências, resultaram descobertas importantíssimas a respeito da existência de períodos críticos para o desenvolvimento das capacidades humanas, ou seja, de períodos nos quais os organismos estão particularmente predispostos a beneficiarem-se da estimulação ambiental. Se o organismo não for adequadamente estimulado na época adequada, 
serão necessários esforços cada vez maiores para produzir alterações num caráter - se é que podem ser produzidas - sendo também cada vez mais alto o custo emocional acarretado. Tais períodos, curiosamente denominados de janelas de oportunidades, já foram identificados para diferentes capacidades. Assim, para a visão, o período crítico encerra-se definitivamente por volta dos dois anos, para música vai dos 3 aos 10 anos, para o desenvolvimento motor, do nascimento ao quarto ano de vida, para matemática e lógica do primeiro ao quarto ano de vida etc.

Referi-me, no início do parágrafo anterior, ao renovado interesse por esse tópico. Empreguei intencionalmente esta palavra para salientar que o interesse não data de nossos dias, uma vez que podemos identificar esta preocupação no começo da década de 60. São exemplos deste interesse a análise de 1000 estudos longitudinais de crescimento, realizada por Bloom, relatada no livro Estabilidade e Mudança nas Características Humanas, publicado em 1964, assim como as observações do desenvolvimento de crianças criadas em orfanatos de Teerã, realizadas por Dennis. O que diferencia, todavia, esses primeiros estudos dos atualmente realizados é a possibilidade trazida por recursos tecnológicos que permitem imagens muito precisas de cérebros de pessoas vivas executando atividades da vida diária. Graças a tais recursos, ampliou-se enormemente o conhecimento sobre o desenvolvimento cerebral e a importância dos estímulos ambientais em tal desenvolvimento, podendo-se afirmar presentemente com bastante segurança, que as primeiras experiências desempenham um papel fundamental na formação da circuitaria ou rede cerebral. Na verdade, sem tais estimulações, o cérebro simplesmente não se desenvolveria. Como decorrência direta de tais descobertas, avulta a importância do ensino pré-primário. A pré-escola assume assim um papel privilegiado como promotora do desenvolvimento infantil, não apenas nos seus aspectos sociais e afetivos, mas também e principalmente cognitivos. Prevejo que nas próximas décadas psicólogos e educadores se debruçarão sobre este período de vida e sobre este ciclo escolar de maneira muito mais intensa e com muito mais interesse do que até agora.

Uma minha outra impressão é a de um avanço contínuo nas concepções cognitivas de desenvolvimento e aprendizagem e de um refluxo da abordagem comportamentalista, não obstante as várias e diferentes propostas de liberalização desta concepção teórica. Se pudermos avaliar o crescimento de uma área de estudos pelo número de revistas especializadas e pela quantidade de livros publicados a cada ano, o quadro que se apresenta é o de uma área pujante e em contínua expansão. No dizer de Eysenck e Keane (1994):

Se for possível julgar a saúde de uma disciplina acadêmica pelo número de seus partidários, então a psicologia cognitiva, com toda certeza está vicejante. (...)

O tamanho deste exército que marcha sob o estandarte da psicologia cognitiva pode ser atribuído, em grande parte, á abrangência cada vez maior com que o termo é utilizado. Praticamente todos aqueles que possuem interesse sobre percepção, aprendizado, memória, linguagem, formação de conceitos, resolução de problemas ou pensamento intitulam-se psicólogos cognitivos, apesar da grande diversidade de abordagens experimentais e teóricas encontradas nestas áreas (p.7).

Parte desta expansão, acredito eu, deve-se ao desenvolvimento e apropriação pela Psicologia da teoria da informação, que vê o aprendiz como um ativo processador de informações. Como salienta Pfromm Netto (1987): 
A pesquisa e a teorização atuais em aprendizagem tendem a realçar cada vez mais os aspectos cognitivos desta, atribuindo importância central às características de aquisição de conhecimento e processamento de informação, em substituição à tônica comportamental dominante na literatura científica das décadas de trinta e quarenta (p. 13).

Um outro aspecto que, no meu entender, atesta o vigor do cognitivismo dentro da psicologia contemporânea é a inclusão da Psicologia Cognitiva como uma das mais importantes disciplinas integrantes da Ciência Cognitiva, esse esforço multidisciplinar que propõe-se investigar a cognição humana, em seus múltiplos aspectos, através das contribuições de diferentes áreas de conhecimento afins, tais como a Lingüística, as Neurociências, a Filosofia, a Inteligência Artificial etc. Esta tendência de estudar um fenômeno não mais de forma isolada, mas aproveitando-se das contribuições de diferentes disciplinas deverá, acredito eu, aprofundar se ainda mais no futuro próximo. Vimos anteriormente, quando falamos da importância das primeiras experiências para os organismos, a profunda implicação das descobertas dos neurocientistas para a compreensão do desenvolvimento de capacidades humanas e para a sugestão de atividades na pré-escola. Aprender a trabalhar em grupo, em equipes multidisciplinares, aproveitando-se de tudo aquilo que realmente interessa ao nosso trabalho e desconsiderando o que é por demais específico, é tarefa a que o psicólogo não pode mais furtar-se.

Chama-me também a atenção, a transformação por que vem passando o conceito de inteligência em nossos dias. Refiro-me particularmente às idéias do psicólogo norte-americano Howard Gardner que, em 1983, publicou um influente livro denominado Estruturas da Mente: A Teoria das Inteligências Múltiplas, no qual defende a existência de vários e diferentes tipos de inteligência, quais sejam: lingüística, musical, lógico-matemática, espacial, corporal-cinestésica e pessoal. Um dos grandes méritos desta postulação, a meu ver, é a de ampliar consideravelmente as competências do ser humano, enfatizando capacidades pouco consideradas e/ou valorizadas na vida diária em geral e na escola em particular. Ao postular a existência de inteligências outras que não as tradicionais inteligências verbal e lógico-matemática, o autor abre caminho para uma consideração mais abrangente do ser humano em geral e do aluno em particular. Mostrando ao psicólogo e ao professor que há muito mais talentos num aluno do que eles costumam admitir, esta concepção teórica pode contribuir para que o aluno seja visto de maneira mais favorável, uma vez que de maneira geral, cada um de nós apresenta uma ou mais dessas inteligências bem desenvolvidas. Reconhecer novas competências e valorizá-las, também pode ajudar no sentido de evitar ou minimizar a estigmatização de alunos com baixos escores nos teste tradicionais de inteligência, que avaliam predominantemente capacidades verbais e lógico-matemáticas - e nem sempre de maneira adequada, mormente para aqueles alunos provenientes de classes sociais economicamente desfavorecidas. Talvez o psicólogo escolar encontre nesta teoria uma maneira de ele próprio encarar de forma mais positiva o desempenho de crianças pobres, de transmitir esta mensagem aos professores, contribuindo, em última análise, para aumentar a auto-estima dos alunos. Em suma, ao invés dos criticados laudos psicológicos, que salientam o que se pensa que o aluno não tem, o que se propõe é a consideração de um repertório maior e mais diversificado de capacidades, que retrate de maneira mais justa o aluno de nossas escolas em geral e das escolas da periferia em particular.

Como anteriormente salientado, as diferentes abordagens aplicadas ao ensino escolar, desenvolvidas nestas últimas décadas, têm se concentrado predominantemente em um aspecto da 
natureza humana: a ação, a cognição e a emoção. Necessário se faz o desenvolvimento de concepções mais abrangentes, que retratem as maneiras pelas quais esses diferentes aspectos se interrelacionam no aluno que aprende. Não obstante, o generalizado reconhecimento da importância de cada um dos fatores de per se, não diviso no horizonte próximo nenhum esforço teórico mais sério no sentido de explicar o processo ensino-aprendizagem levando em conta o peso relativo de cada um dos fatores. A menos que tal teoria seja desenvolvida, continuaremos a ver o aprendiz de maneira parcial e incompleta, ou como um organismo que apenas atua sobre o meio, ou como um ser que unicamente processa informações e as representa internamente sob a forma de conhecimento ou, finalmente, como alguém que somente aprende de maneira significativa se impelido pelas emoções. A complexidade do ser humano merece certamente uma teoria mais completa.

Chego agora, ao final de minha palestra. Procurei com ela dar um testemunho da maneira pela qual eu vejo as interfaces entre a Psicologia e a Educação. Na medida em que tal testemunho é pessoal, refletindo minhas vivências particulares e minha interpretação idiossincrática das informações coletadas, muitos dos que me ouvem discordarão de algumas ou, talvez, de todas as colocações feitas. Certamente, insuficiências serão assinaladas e discordâncias quanto às perspectivas futuras da relação Psicologia e Educação apontadas. Apesar desta possibilidade de questionamento, acredito que valeu a pena trazê-las à análise crítica desta informada platéia de psicólogos. Renovo, pois, os meus agradecimentos à Diretoria da ABRAPEE pela possibilidade de trazê-las à consideração de todos vocês. Muito obrigado!

\section{Referências}

Eysenck, M. W. e Keane, M. T. (1997). Psicologia Cognitiva; Um Manual Introdutório. Porto Alegre: Artes Médicas.

Gardner, H. (1995). A Nova Ciência da Mente: Uma História da Revolução Cognitiva. São Paulo: EDUSP.

Pfromm Netto, S. (1987). Psicologia da Aprendizagem e do Ensino. São Paulo: EPU.

Spinillo, A. G. e Roazzi, A. (1989). A atuação do psicólogo na área cognitiva: reflexões e questionamentos. Psicologia: Ciência e Profissão, v. 3, 20-25.

Travers, R. M. W. (1972). Essentials of Learning. New York: Macmillan. 